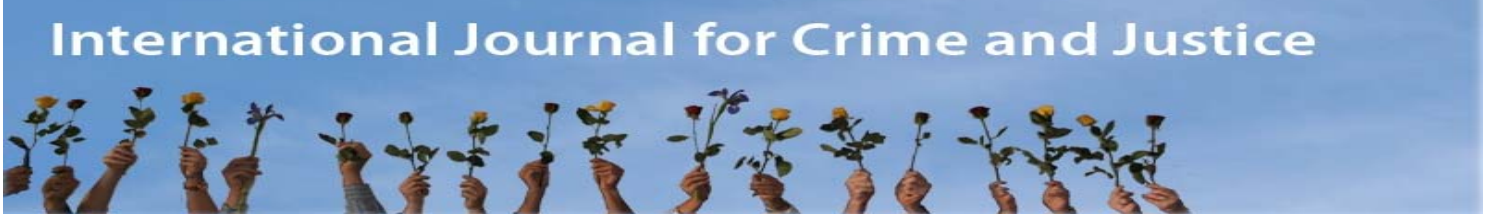

\title{
Engaging the Public in the Development of Sentencing Policy
}

\author{
David Indermaur \\ University of Western Australia, Perth
}

\begin{abstract}
The issue of the lack of confidence in the courts provides an opportunity for us to consider the question of how sentencing policy is formulated and whether there is room for improvement in the process. It is argued in this paper that the legitimacy of the courts and public satisfaction with sentencing can both be enhanced if we were to carefully provide for the inclusion of an informed and deliberating public into policy formulation. Such a strategy would not only quell the loose and ill-defined 'public opinion' that characterises the tabloids; it would also enhance the transparency and the public acceptance of policy. The paper considers the continuum of possibilities for including the public from the gratuitous exploitation of the public voice by populists and media entrepreneurs using top-of-the-head opinion polls through to informed public opinion, public consultation process and ultimately the democratisation of sentencing policy. It is argued that this continuum can be seen as reflecting both the amount of true power given to the public voice as well as the amount of respect given to public input. Much of the fear of public inclusion in elite circles concerns public opinion as depicted in the media which is largely 'public emotion'. It is argued that, when properly integrated, the inclusion of the public voice in the policy formulation process will have the same salutary effect that the jury has on the criminal trial.
\end{abstract}

\section{Keywords}

Sentencing policy, democratisation, public opinion, confidence in sentencing, deliberation, public engagement.

\section{Introduction}

The issue of the lack of confidence in the courts seems to strike a chord with the judiciary, the public and politicians alike. Although there are many problems with the concept, as will be discussed below, it is important at the outset to note the deep resonance of the issue. Why does it resound so deeply? One reason may be that it reflects an even greater crisis of trust in government and our public institutions. The charge that the courts are 'out of step' may sting because it has become a social and political fact, notwithstanding the widespread lack of knowledge about the courts. The reality for most is that the courts don't look like a responsive, transparent or accountable organisation. This may well be because these characteristics were never seen as vital performance indicators for courts. They were, in previous times, more concerned with exhibiting their insularity along with, or supported by, the sober and elite status they enjoyed. But times have changed and the crisis of confidence in the courts is perhaps reflective of the emerging view that the courts need to catch up. Authority remains the key 
characteristic but legitimacy needs to be found through those more ascendant characteristics mentioned above such as accountability, responsiveness and transparency.

The problem of 'face validity' or legitimacy can be traced back to the way policies that govern the operation of the courts are developed. Conventional mechanisms that provide for the development of policy by the elite effectively block out the public from a serious role in policy formation. However in systematically blocking the public out of formal channels, the public 'voice', at least as it is perceived and conceptualised by some actors, may exercise an even greater influence. Ironically that influence may further distance the real 'voice' of the public. The 'public opinion' that is being taken on board by populists is a kind of media dominated and reactionary caricature and bears little relation to more considered public judgment. It is argued in this paper that the public could be more effectively engaged in the policy development process. Democratisation provides the possibility of positive engagement of the public. As such it is argued that democratisation sits at the opposite end of a continuum of public engagement from the dominant political strategy of populism.

The paper begins with an exploration of the nature of informed public opinion and the contribution that 'deliberation' makes to attitudes to sentencing. It will be argued that the way sentencing policy is formulated can be reformed to provide a greater degree of public accountability and transparency. This is the development of policy through the inclusion of the public voice. At this point I would expect most readers from the judiciary would be tensing up a little so I would hasten to add that the argument is that, when properly managed, a thoughtful and genuine inclusion of the public voice will not only provide for more valid and acceptable sentencing policy, it will also increase the authority of the courts.

\section{Vox populi?}

The idea that the voice of the public is important is rarely contested. What is the subject of fierce debate is what can be taken as a meaningful or accurate representation of that voice. What we know is that the tool most commonly used, the opinion poll, is a very unreliable measure. This is because the responses are largely dependent on the context and question asked ${ }^{1}$. The thoughts and positions adopted by a member of the public in relation to a question are invariably a reflection of some embedded assumptions contained within an ongoing discourse around the topic. For example, if the questions relate to gun control, the death penalty or mandatory sentencing, they invite the statement of the respondent's position based on what has already be gleaned about debate contained in the news media. Essentially the poll is asking about the respondent's alignment with established socio-political interests. Presenting this as simple 'opinion' without acknowledging predictable factors conditioning the response is either misleading or misinformed. However, the 'top-of-the-head' response will continue to be interesting to many. This is not necessarily a problem as long as there is a clear appreciation of what is being measured. This kind of polling is interesting precisely because it is tapping into the affective or feeling level rather than a considered judgment. Because of this, the term 'public opinion poll' should really be renamed 'public emotion poll'.

Emotions of fear, anger and disgust are certainly easy to elicit on topics of crime and punishment ${ }^{2}$. However, to reduce public input to that of emotional reaction denies the legitimate and more pragmatic public interest in policy. Doob (2000) found that when conditions for rational problem solving are established it is the utilitarian aims that predominate. So the problem or obstacle for including the public voice into the development of policy is not with the public but with the way the public is engaged. When engaged as decision makers rather than as robotic responders to polls, the more detailed and responsive preferences of the public can be isolated. Doob found, unsurprisingly, that, when policy options were posed in a more detailed way with alternatives and consequences, members of the public respond logically in the same way we would expect of responsible decision makers with a view 
to optimising public benefits. The options chosen are those that would reduce victimisation most and lead to the greatest effect in terms crime reduction.

Part of the reason polls constructed to focus on practical policy decisions are not conducted or reported on is that they are not newsworthy. As Katz (1987) notes, the media consistently select issues that will raise conflict and outrage. Staying focused on the issue of whether the public want tougher or more lenient sentencing and whether they trust or don't trust the courts will set up the answers to fall in a certain direction that fulfil media needs. They reveal an interest in the emotional dimensions of the punishment response rather than what the public might want from policy. The top-of-the-head polls serve to keep the focus on expressive aspects of sentencing because they invite and reflect personal values or emotions. Such a focus is cued to respondents by the general, and often directly emotional, nature of the questions. This focusing on values and emotions plays directly into the central and pervading concerns of morality, responsibility and social defence. This is the reason why crime is such an effective target for expressive emotions and politics. This is also why populism always presents as somewhat colourful and media friendly. A populist and a media entrepreneur both feed off the rich field of public emotion. This leads to a toxic tryst between media and politics. The media provides the perfect vehicle for the populist strategy of privileging emotion over reason. It is the experience of exuberance which comes from the emotional release and the abandonment of reason. Such a release feels exhilarating and provides ready-made product for the tabloid and broadcast media. Crime control is not interesting to populists because of a realistic threat of victimisation but rather because crime represents par excellence a range of other breakdowns in social institutions and relations through which individuals feel disempowered (see Tyler and Boeckmann 1997).

So we need to acknowledge a split here between the interests of the news media for titillation and emotional stimulation rather than rational reflection and consideration of policy options. By continuing to focus only on the emotional or expressive dimensions of the punishment response, media and political entrepreneurs are able to exploit 'the voice of the people' for their purposes. This is fundamentally disrespectful of the public and dismisses it as a viable force within policy development. The 'public' as an entity is reduced to a repository of raw emotion. For this to change, the public does not need to be 'informed' or 'educated'; rather, the expectations of the role of the public must be different. If we are interested in the considered view of members of the public on a certain policy matter and we are prepared to take the time to apprise the respondent of the relevant information as well as the constraints and implications of various policy options, we are entering a different enterprise. This takes the form of various shades of what can generally be described as 'informed public opinion'.

Focusing on informed public opinion essentially changes the interest from opinion as a kind of 'word association test' to one where the inquiry is focused on what the view or judgment is when the respondent has some knowledge of the question at hand. But the notion of informed public opinion generally conveys more than just knowledge or 'information'. Price and Neijins (1998) argue that there are three elements of the construct: information; deliberation; and responsibility-taking. It is significant that two of Price and Neijins' criteria do not concern information but rather the orientation of the respondent to the task. These authors see the processing of the information through question, debate and consideration as constituting the 'lion's share' of what we mean when we talk about informed public opinion. The study of informed public opinion therefore leads into the investigation of deliberation, a term that could be seen as containing the core process of informed public opinion ${ }^{3}$. Informed public opinion has been incorporated into a range of methods designed to provide a meaningful reflection of public views and responses to specific issues. These include planning cells, deliberative polling, consensus conferences, citizen panels and citizens' juries. Common to all these is the deliberative component where participants are provided with information about the issue being 
considered, are encouraged to discuss and challenge the information, and to consider each other's views before making a decision or recommendation for action.

So we have two extremes in considering potential public contributions to policy. First, the topof-the-head opinion reflected in the polls we often see in newspapers; and second, the other deeply considered judgment contained within certain parameters and guided by elaborate 'rules' of evidence and the like. Naturally these serve very different purposes but they reflect in some degree the evolution of our thinking about public attitude, from being just lightly held opinion to considered judgment. This distinction has actually been appreciated for a long time but has yet to become widely accepted or incorporated into policy formation mechanisms. In the distinction Habermas (1989 [1963]: 219) makes between 'mere opinion' and 'public opinion', he reveres the latter as not simply the collection of individual views ('mere opinion') but rather the 'evolution' of such individual views as a result of rational critical debate. It is this process of debate which is critical. The debating process requires attention, the formulation of positions and the process of defending the position formulated. It is this process that ultimately distinguishes what Habermas calls 'mere opinion' from its alternative: considered judgment. The process is elevated by the requirement that the respondent needs to weigh up competing goals, sensitivities and constraints to arrive at a responsible decision. Studies of public attitudes have found this to be a crucial shift that informs and colours the outcome significantly. For example, Durham and colleagues (1996) found that support for the death penalty decreased substantially when respondents were placed in more of a decision-making role by being presented with a case vignette rather than with a simple 'do you favour ...?' question.

The crisis of confidence or legitimacy in the courts is exacerbated by superficial polling which appears to reinforce and amplify public discontent with the courts. Some may argue that there is nothing wrong with providing punishment which may be expressive but not based on rational consideration. But this simply puts sentencing in the position of the domestic cat that is kicked as an outlet for frustrations developed elsewhere. It follows that if we are to have a rational or responsible sentencing policy, it is fundamental that the expressive value of punishment needs to be named as such so that it is not confused with a considered or accountable policy. Further, unless we accept the notion that crime policy should simply serve as a means for the public venting of frustrations, we need to find a way of addressing the conflict between responsible policy making and popular punitiveness.

The systematic and responsible engagement of the public may provide an important means not only to provide greater legitimacy to the courts but also to protect them from political exploitation. The possibility of shutting out the public voice or placating it seems to be the least effective as well as the least creative way of responding to the crisis of confidence in the courts. Effective engagement offers a much more liberating and satisfying prospect. Ways to achieve effective engagement need to be seriously accelerated. As a start we need to scope out the issues regarding engagement.

\section{Levels of public engagement}

Ways of engaging the public can be sketched from the reactionary to the progressive. Although populist responses appear to privilege the public and provide the public a royal road to the articulation of policy, this view is flawed because of what is accepted as a representation of 'the public'. What are privileged are the perceived public emotions rather than the considered view of a representative sample of the public. The position is akin to substituting a jury verdict with the kind of viewers' poll regularly incorporated into commercial news broadcasts. A true engagement of the public needs to start from a position of respecting and valuing public input and providing the conditions where public judgment can be accurately captured or reflected. 
In considering the role of the public in the reform of crime policy, Dzur (2012) argued that political and legal theorists have offered two diametrically opposed responses. On the one hand, he argued, are the insulations who seek to isolate and protect special and sensitive aspects of the criminal justice system such as sentencing from the vague and fierce winds of public influence. This position is reflected in the suggestions by some in this area (for example, Roberts et al. 2003) for the development of 'institutional buffers' such as Sentencing Advisory Councils. However, Dzur details the flaws of the insulationist position ${ }^{4}$ and concludes that it provides insufficient protection from the seductions of populism:

... the insulationist approach to penal policy is fundamentally flawed. Given these flaws, it should be seen as acceptable only if it is better than the alternative. Thus far, the alternative has been characterized as the status quo condition of penal populism, but this is not the only available choice. (Dzur 2012: 118)

The contrasting position is that, rather than deflect public influence, we should systematically and effectively embrace it. The alternative, according to Dzur, is the 'integrationist' position reflected in the work of John Braithwaite, Nils Christie and Howard Zehr. Dzur argues it is the latter approach which offers much greater advantages in moving forward due to the practical and normative problems with the insulationsist approach.

While much of the work Dzur talks about in regard to integrating the public voice involves the restorative justice movement and juries, he acknowledges that the level of public involvement with these aspects of the operation of the criminal justice system are relatively small and often perfunctory. The real possibilities of reform lay with the integration of the public voice into the development of policy. There have, to this point, only been the fledgling attempts represented by one or two experiments with deliberative polling to speak of. The idea of systematically integrating the public voice into the formation of sentencing policy clearly lays some distance in the future.

As noted above, the alternative ways of viewing attempts by authorities to situate the public voice can be placed on a continuum from the gratuitous and exploitative (populism) to detailed, genuine and considerate. This continuum has been described in detail in an earlier work (Indermaur 2008). Dzur's binary distinction between insulationists and integrationists can be seen as looking at the two points on this continuum. Once we see how the struggle to incorporate and respond to public opinion falls on a continuum, we can begin to see the underlying domain reflected in the continuum. It could be summarised as 'power' - the actual power, reflected in respect given to the public voice. This essential property of the continuum could be seen as somewhat akin to the concept of 'dominion' within the republican theory of justice

The integrationist approach is obviously consistent with the attempt to enhance public engagement in sentencing policy. It aligns with the movement away from the simple tapping of top-of-the-head opinions and towards placing the public in a position of respect and responsibility. As a decision maker, the way individuals approach and respond to matters before them changes. To provide a meaningful response, the respondent needs to be able to be briefed on important and relevant information and be able to access more information that they perceive may be necessary or relevant in their role as a decision maker. In much the same way as a group of the public in the form of a jury are fully apprised of the evidence and are able to seek more information when a group of the public are invited to have a role with some responsibility to establish parameters for sentencing policy, they need to be engaged in an interactive way when it comes to information ${ }^{5}$.

The problems seen in recent attempts by governments to involve the public directly through polls, referenda or consultations have been discussed elsewhere (see Indermaur 2008). These 
earlier attempts were misinformed and dangerous. For example, the idea of including a one sentence question as a referendum at the national election in New Zealand provided broad authority for the most draconian sentencing measures. Further, the enthusiasm amongst government agencies large and small for 'consultation' does little to provide for the realistic inclusion of the public voice. Traditional/formal government consultation processes ('respond if you want') appear to be the most disingenuous as they attempt neither representativeness nor the systematic exploration of public views and judgment. Public engagement needs to be built on a well informed and constructed plan. It is not something that can be conducted cheaply or quickly. Ideally these attempts to engage the public should be theoretically grounded and inspired. This would mean that, rather than consultation 'add-ons' to an already established policy formulation process, the public input becomes an essential part of the process. The guiding principles of democratisation would then replace the existing mantra of 'consultation' and the inherent understanding that it is an expendable side dish. We have seen various attempts at a consultative process emerging in England and Wales following (and including) the Home Office (2001) review of sentencing (the Halliday Report). However these attempts have been criticised (see Indermaur 2008) as they fell well short of what could be described as comprehensive or genuine. Whilst the development of the Sentencing Advisory Panel provided for independent measures of public attitude, this is still a long way from the democratisation of sentencing policy ${ }^{6}$.

Despite the stilted, patchy and limited attempts to include the public voice in the area of criminal justice policy, democratisation is well under way in other areas social policy ${ }^{7}$. Dzur and Mirchandani (2007) see the democratisation process as occurring through the escalation - or rather the introduction - of a greater sense of public participation and dialogue. These authors point to the restorative justice movement and the supporting republican theories of justice as offering a stark alternative to the passive democratic processes that lead to the dead end of populism. The power of populists and the media to take the moral high ground can continue for only so long as they can purport to speak for that mystical figure 'public opinion'. Such claims can be cut down by establishing a robust process of public engagement that truly involves the public and brings them into the key decision making framework.

\section{Creating vitality in policy}

The issue of confidence in the courts needs to be seen in the larger context of changing perceptions and expectations of government and government institutions. The ground has shifted and old certainties and assumptions of respect for elites no longer apply (Ryan 2004). Along with the advent of corporate mission statements, freedom of information and continuous commissions and inquiries into all arms of government come new expectations of transparency and accountability. These expectations spread to the courts themselves, their actions (the sentencing) and the policy that underpins sentencing. We find old assumptions that elites are to be respected as a kind of benign and knowing repository of wisdom on matters concerning the law are no longer sufficient. Sentencing policy, perhaps one of the most vital and expressive forms of government policy, appears to be at the frontline for criticism but reform of the way sentencing policy is formulated appears to be lagging well behind what is required. In her penetrating analysis of the issue of public confidence of the criminal justice system and the surrounding discourses, Turner (2008) argues that the concept of confidence needs to be more thoroughly examined and a clearer emphasis put on meaningful engagement. Turner makes the point that the concept of confidence in the courts should not be taken on face value. Digging deeper reveals the issues discussed above which largely pertain to trust and the compact that does, or does not, exist between the public and the institution.

As in other areas of policy that have attempted to provide a place for public input, it is regularly concluded that, unless the effort is genuine and carefully managed, it is likely to backfire and create even greater cynicism. The first question, then, is: 'are we genuine?' Do we really want to 
provide a meaningful place for the public voice in the development of sentencing policy? Many of the attempts to include the public in criminal justice policy making thus far appear half hearted. As Johnstone (2000) notes, many of the vaunted public consultations appear to have been largely designed simply to placate the public.

A key question for those interested in democratisation is where public input is best placed. Some systematic thinking and planning here would go a long way to provide for reasoned public input. Incorporating compartmentalised and sequential stages could be useful. For example, at the initial stages, an examination of public preferences around overarching goals, principles and balancing priorities could be undertaken ${ }^{8}$. Such considerations have been undertaken by many of the formal reviews of sentencing conducted in most western democracies over the past quarter century. However, these have rarely systematically tapped public preferences. Following on from the general level, there could be an inquiry into managing different types of sentencing dilemmas. An interesting challenge is to genuinely inquire how sense is made of different offence/offender combinations. We know from various research into public opinion (for example, Rex 2002) that the public think in terms of offence/offender combinations. One of the possibilities is to explore how public conceptualisations might be translated into different 'pathways' of justice in a way outlined by Freiberg (2002). This might make the practice of sentencing fit better with how individuals think about sentencing. Not only might this increase legitimacy, it will aid in the communication of the intent and process of sentencing.

What is impractical and unnecessary in regard to public engagement is for the public to be engaged in operational and administrative matters. It is at the level of overarching policy and direction that public engagement is not only most meaningful but ultimately (for the public and the courts) likely to be most satisfying. The technical detail of how to give effect to these principles is more the province of 'legal technicians' - the administrators of the criminal justice system who have the task of ensuring that the administration of criminal justice is fair and gives effect to the legislated aims and principles.

A legitimate public involvement would clearly seek to incorporate and harness the views of 'Joe public', the ordinary everyday citizen that does not have a particular axe to grind but is concerned with the things most citizens can be thought to be concerned with - public safety and the integrity and fairness of the criminal justice system. What we are seeking here is the recruitment and engagement of a representative sample which would be willing to become at least modestly informed about some relevant facts about crime and the possible functions of punishment. Following this, there has to be room for some debating process where views can be put forward, tested, responded to, and so on This process is necessary to test the robustness of certain views and explore what is essential and what is more peripheral or expendable in public wishes concerning sentencing The debating process also tests out how public views can respond and change with the addition of information - like the technical likelihood of changing behaviour, producing more public safety, the relative costs of certain proposals and perhaps some of the unanticipated consequences. The process parallels the 'public sphere' processes introduced and discussed by Habermas. As Dzur and Mirchandani (2007: 161) summarise:

... public sphere process involve[s] individuals who interact equally in rational, open and ongoing debate to discuss and ultimately agree upon public policies like punishment. By rational debate Habermas means a process already inherent in basic language use where people make claims, give reasons for their claims and, given adequate time, reach consensus or agreement. A rational debate on public policy involves articulating, explaining or justifying positions.

From this process of providing information and debate, we can arrive at a set of principles and priorities. These can be integrated into a cogent policy framework through mechanisms 
developed in policy bureaux and ultimately integrated in a practical way into legislation that governs sentencing practice.

Creating a context of decision making whereby the responsibility for policy rests with the individual will likely reduce many participants' tendency to base their responses on pure emotion. The same sobering process can be observed in the jury where coming to a verdict places great responsibility on members of a jury. In the same way we expect ordinary citizens to rise to the occasion as members of a jury, we can expect members of a citizen policy panel to rise to the occasion and contribute honestly and for the benefit of the community. The key issue is not information but the role we expect the respondent to play and how we convey that expectation through how the respondent is approached. Indermaur and colleagues (2012) concluded from their analysis of the impact of information and deliberation on short form opinion surveys that, rather than the technical information, it was the changed task demands or postures that made the difference in terms of reduced punitiveness and increased openness to alternative to imprisonment. Information is still obviously vital but now this is seen as something provided to help individuals with their decision making. Again, the model of the jury can guide us in how to appreciate and value the judgment of the public and incorporate it into the process with real meaning.

There is considerable experience on how to provide for public participation in developing policy, including complex areas of social policy ${ }^{9}$. This points to the necessity of a multi-layered strategy where policy questions are carefully formulated prior to any attempt at formally engaging the public. In the preparation stage, components or aspects of sentencing policy, where it is valuable to obtain public input, need to be identified by a suitably qualified group and then questions developed where public preferences or responses are relevant. This initial stage could involve key groups of stakeholders, as has been the practice elsewhere, to help frame relevant questions for the public debate (see Renn et al. 1993). This stage also involves developing a range of policy positions and questions. Policy options need to be formulated and embellished with vital information such as cost benefit analyses and other considerations to allow meaningful and realistic policy options to be posed in an appropriate way to a sample of the public.

The idea of deliberative polling or a citizen jury on sentencing being developed and conducted by a suitably qualified and independent body has significant advantages. Thus far the most widely cited deliberative polling exercise in regard to criminal justice was actually organised and conducted by a television station. Independent researchers are unlikely to be able to have the infrastructure or funding to be able to conduct the complex and expensive exercise required. The endeavour clearly needs to be government funded but also needs to be kept at arm's length from current governments. The ideal authority exists in some jurisdictions in the form of Sentencing Advisory Councils. Indeed, as noted earlier, the Sentencing Advisory Panel in England and Wales conducted a number of specific and detailed inquiries into public opinion regarding some difficult sentencing policy dilemmas. In Australia, the Victorian Sentencing Advisory Council has conducted a series of inquiries and sponsored research into public opinion on sentencing matters. In New South Wales, the Sentencing Advisory Council has funded research conducted by the NSW Bureau of Crime Statistics and Research into confidence in the courts. These are all positive starts and augur well for the future but they remain fixed to the old notion of using traditional methods of gauging public opinion. There is clearly more than can be done and needs to be done as suggested above.

There may be a belief amongst some in the judiciary and academia that sentencing is too important to be entrusted to the public but this position (insulationism in Dzur's analysis) essentially turns the democratic process on its head; ultimately it is the public through its elected representatives who will determine the guiding purposes of the sentencing and the level of punishment that should be assigned to various offences. It is perhaps the perceived attempt 
by elites to retain power over the processes and priorities that govern sentencing that underlies much of the public outrage. The public are entitled to feel that the compass used to reflect the careful balancing of safety, justice and morality belongs to the community.

\section{Conclusion}

This paper began with the question of why the issue of confidence in the courts is widely recognised as one that should be addressed and needs to be addressed. The key argument here is that the issue pertains to the ever growing lack of legitimacy of the courts. This is not because the courts are doing anything differently or that they have failed to adhere to their own expectations. Rather it is because the policy that governs the courts and that the courts enact, principally sentencing policy, is not seen as transparent or publicly accountable. The crisis of confidence is in essence a crisis of legitimacy. The crisis will remain until sentencing policy can open up to wider influence, in particular some form of public input. The sense of aloofness and elite control will continue to hamper any effort by governments of judiciary to 'sell' the policy unless some form of public input has been integrated into the formulation of policy.

The value of public engagement is principally to add legitimacy to the courts. However the process of public engagement will do more. It will add value to the communicative functions of the court. The process of articulating and explaining policy options is likely to be a salutary discipline and enhance the public appreciation of both policy and practice. Juries have provided a great deal of legitimacy to criminal trials and to a greater or lesser extent fireproofed verdicts from public criticism. The jury system has also been instrumental in shaping legal process. This form of public engagement has not had the effect of wrestling control of the criminal process away from the judiciary. Indeed this form of engagement adds legitimacy while strengthening the process and ultimately the authority of the courts. A corresponding form of public engagement could provide the same service to sentencing policy and ultimately enhance the legitimacy of that policy and the confidence people have in the courts.

Correspondence: David Indermaur, Associate Professor, Crime Research Centre, University of Western Australia, Crawley WA 6009, Australia. Email: david.indermaur@uwa.edu.au.

1 A number of authoritative sources provide detail on the picture of public opinion, the media and sentencing practice referred to here. Roberts and Stalans (1997) provide the most detail and complete reference. A more accessible reference is Roberts (1992) or Cullen et al. (2000). In regard to the media and political exploitation of public concerns, see Roberts et al. (2003) or Indermaur and Hough (2002).

2 The exploration of public emotions around crime and sentencing has had a long history and has had something of a resurgence of interest recently. See Karstedt (2002) for a discussion of the emotionalisation of the law, Johnson (2009) for a review of the role of anger in public attitudes. See Sargent (2004) for an examination about how individual preferences to use emotion in understanding behaviour can predict punitiveneness and Frieberg (2001) for an appeal to policy makers to consider the emotional dimension or public opinion as an important issue to consider when shaping and presenting criminal justice policy.

3 See Barabas (2004) for an investigation of how the term 'deliberation' has evolved and what the active processes involved are.

4 The key arguments Dzur mounts against insulationism are that '... it depends upon a political condition ... that no longer holds in the United Kingdom or the United States namely trust in experts and professionals in criminal justice' (p. 117). Second, Dzur argues that the idea of true independence is questionable as the selection of the chosen few would be subject to political pressures. Finally, Dzur argues the expert panel system does little to protect the political masters from criticism once a sensational case draws attention to sentencing.

5 Warner and colleagues (2011) recently report on a study examining how the views of jury members supported the sentencing of the judge at the trial they were involved in and the information and deliberation on the judges' reasons for sentencing generally had a moderating influence on their views about sentencing in general.

6 The Sentencing Advisory Panel greatly increased the quality of the measurement of public attitude and developed specific inquiries into public attitude in regard to certain key areas of sentencing reform (for example Roberts et al. 2009). The Sentencing Advisory Panel was superseded along with the Sentencing Guidelines Council in 2010 by the newly established Sentencing Council for England and Wales.

7 For an overview see Goodwin and Dryzek (2006), Dryzek (2000), Bessette (1994) and Gastil and Levine (2005). 
On this topic see Roberts et al. (2009)

9 For example see: Catt and Murphy (2003), Goodwin and Dryzek (2006) Ackerman et al. (2004) Smith and Wales (2000), Shand and Arnberg (1996), Bishop and Davis (2002), Hendricks (2002), Einsiedel and Eastlick (2000), Pratchett (1999); Fischer (1993), Carpini et al. (2004) and Rowe and Frewer (2005).

\section{References}

Akkerman T, Hajer M and Grin J (2004) The interactive state: Democratisation from above? Political Studies 52: 82-95.

Barabas J (2004) How deliberation affects policy opinions. American Political Science Review 98(4): 687-701.

Bessette J (1994) The Mild Voice of Reason: Deliberative Democracy and American National Government. Chicago: University of Chicago Press.

Bishop P and Davis G (2002) Mapping public participation in policy choices. Australian Journal of Public Administration 61(1): 14-29.

Carpini M, Cook F and Jacobs K (2004) Public deliberation, discursive participation and citizen engagement: A review of the empirical literature. Annual Review of Political Science 7: 315344.

Catt $\mathrm{H}$ and Murphy M (2003) What voice for the people? Categorising methods of public consultation. Australian Journal of Political Science 38(3): 407-421.

Cullen F, Fisher B and Applegate B (2000) Public opinion about punishment and corrections. In Tonry M (ed) Crime and Justice: A Review of the Research, Volume 27. Chicago: University of Chicago Press: 1-79.

Doob A (2000) Transforming the punishment environment: Understanding public views of what should be accomplished at sentencing. Canadian Journal of Criminology 42(3): 323-340.

Dryzek J (2000) Deliberative Democracy and Beyond. Oxford: Oxford University Press.

Durham A, Elrod P and Kinkade P (1996) Public support for the death penalty: Beyond Gallup. Justice Quarterly 13(4): 705-736.

Dzur AW (2012) Participatory democracy and criminal justice. Criminal Law and Philosophy 6: 115-129.

Dzur AW and Mirchandani R (2007) Punishment and democracy: The role of public deliberation. Punishment and Society 9(2): 151-175.

Einsiedel E and Eastlick D (2000) Consensus conferences as deliberative democracy. Science Communication 21: 323- 343.

Fisher F (1993) Citizen participation and the democratisation of policy expertise: From theoretical inquiry to practical cases. Policy Sciences 26: 165-187.

Freiberg A (2001) Affective versus effective justice: Instrumentalism and emotionalism in criminal justice. Punishment and Society 3: 265-278.

Freiberg A (2002) Pathways to Justice Sentencing Review 2002. Melbourne: Victorian Sentencing Advisory Council.

Gastil J and Levine P (eds) (2005) The Deliberative Democracy Handbook: Strategies for Effective Civil Engagement in the Twenty First Century. San Francisco: Jossey-Bass.

Goodwin R and Dryzek JS (2006) Deliberative impacts: The macro-political uptake of mini publics. Politics and Society 34(2): 219-244.

Habermas J (1989 [1963]) The Structural Transformation of the Public Sphere: An Inquiry into a Category of Bourgeois Society (trans. Thomas Burger). Cambridge MA: MIT Press.

Hendricks C (2002) Institutions of deliberative democratic processes and interest groups: Roles, tensions and incentives. Australian Journal of Public Administration 61(1): 64-75.

Home Office (2001) Making Punishments Work: Report of a Review of the Sentencing Framework for England and Wales (the Halliday Report). London: Home Office Communications Directorate. 
Indermaur D (2008) Dealing the public in: Challenges for a transparent and accountable sentencing policy. In Freiberg A and Gelb K (eds) Penal Populism, Sentencing Councils and Sentencing Policy. Annandale, NSW: Hawkins Press: 45-67.

Indermaur D and Hough M (2002) Strategies for changing attitudes to punishment. In Roberts J V and Hough M (eds) Changing Attitudes to Punishment: Public Opinion, Crime and Justice. Cullompton, UK: Willan: 198-214.

Indermaur D, Roberts L, Spiranovic C, Mackenzie G and Gelb K (2012) A matter of judgment: The effect of information and deliberation on public attitudes to punishment. Punishment and Society 14(2): 147-165.

Johnson D (2009) Anger about crime and support for punitive criminal justice policies. Punishment and Society 11: 51-66.

Johnstone G (2000) Penal policy making: Elitist, populist or participatory? Punishment and Society 2: 161-180.

Karstedt S (2002) Emotions and criminal justice. Theoretical Criminology 6(3): 299-317.

Katz J (1987) What makes crime news? Media, Culture and Society 9: 47-75.

Pratchett L (1999) New fashions in public participation: Towards greater democracy? Parliamentary Affairs 52: 616-634.

Price V and Neijens P (1998) Deliberative polls: Towards improved measures of 'informed' public opinion. International Journal of Public Opinion Research 10: 145-176.

Renn O, Webler T, Rakel H, Dienel P and Johnson B (1993) Public participation in decision making. Policy Sciences 26(3): 189-214.

Rex S (2002) Reinventing community penalties: The role of communication. In Rex S and Tonry M (eds) Reform and Punishment: The Future of Sentencing. Cullompton UK: Willan: 138-157.

Roberts J (1992) Public opinion, crime and criminal justice. In Tonry M (ed) Crime and Justice: A Review of Research, Volume 16. Chicago: University of Chicago Press: 99-180.

Roberts J and Stalans L (1997) Public Opinion, Crime and Criminal Justice. Boulder, CO: Westview Press.

Roberts J, Stalans L, Indermaur D and Hough M (2003) Penal Populism and Public Opinion: Lessons from Five Countries. New York, NY: Oxford University Press.

Roberts J, Hough M, Jacobson J and Moon N (2009) Public attitudes to sentencing purposes and sentencing factors: An empirical analysis. Criminal Law Review November: 771- 782.

Rowe G and Frewer L (2005) A typology of public engagement mechanisms. Science, Technology and Human Values 30(2): 251-265.

Ryan M (2004) Red tops, populists and the irresistible rise of the public voice(s). Journal for Crime, Conflict and the Media 1(3): 1-14.

Sargent M (2004) Less thought, more punishment: Need for cognition predicts support for punitive responses to crime. Personality and Social Psychology Bulletin 30(11): 1485-1493.

Shand D and Arnberg M (1996) Responsive Government: OECD Background Paper. Paris: OECD.

Smith G and Wales C (2000) Citizens juries and deliberative democracy. Political Studies 48: 5165.

Turner L (2008) Public confidence in the criminal justice system: The impact of dominant national-level discourse on research and practice. Crime Prevention and Community Safety 10: 174-189.

Tyler TR and Boeckmann RJ (1997) Three strikes and you are out, but why? The psychology of public support for punishing rule breakers. Law and Society Review 31: 237- 264.

Warner K, Davis J, Walter M, Bradfield R and Vermey R (2011) Public judgment on sentencing: Final results of the Tasmanian Jury Sentencing Study. Trends and Issues in Crime and Criminal Justice 407. Canberra: Australian Institute of Criminology. 